\title{
AN INTEGRATED APPROACH TO TEACHING AND LEARNING LAW: THE USE OF STUDENT PEER MENTOR GROUPS TO IMPROVE THE QUALITY OF STUDENT LEARNING IN CONTRACTS
}

\author{
PETER JM MACFARLANE \& GORDON JOUGHIN*
}

\section{INTRODUCTION}

Increasing student numbers and decreasing education funding threatens to perpetuate a number of significant, interrelated problems in undergraduate legal education. These problems are epitomised by the following characteristics of teaching and learning which we believe are not uncommon in Australian legal education:

- Teaching occurs in large classes (which are at their largest in the crucial first year).

- Students are given little opportunity for interaction, selfdirection, cooperative learning, or for debating ideas among their peers.

- Students often feel alienated, conscious of their perceived "lack of knowledge" and, in spite of their obvious success in previous study, concerned about meeting the high expectations placed on them.

- Teaching methods centre on lectures as a focus for transmitting instrumental knowledge, supplemented by seminars or tutorials, which often develop into mini-lectures.

- Students constantly look to the academic for "answers" as to "what is the law"; they often commit the resulting information to memory and regurgitate it in examination scripts, before 
forgetting it. The students move on to the next year, often with their first love of learning lost.

Legal educators are faced not only with these problems but also with growing demands to address issues concerning the quality of teaching and learning in their subjects. And while traditional methods such as the lecture and seminar continue to dominate undergraduate legal education, increasing use is being made of less traditional, more innovative teaching and learning methods, exemplified by the use of materials-based learning (using computers and other media), the development of real life as well as simulated clinical situations and the introduction of more active learning methods within the classroom.

It was against this background of well recognised problems ${ }^{1}$ and the search for solutions, that the Contracts subject in the Queensland University of Technology's LLB course was redesigned. $^{2}$ This commitment to doing something about the problems outlined above coincided with a major review of the LLB curriculum, making the environment ripe for developing teaching and learning methods more appropriate for first-year law students.

This paper reports on this redesign, first by considering the total teaching and learning environment of the subject and then by focusing on that aspect of the new environment which we consider unique to legal education in Australia - the student peer mentor group.

\section{A MODEL FOR TEACHING AND LEARNING LAW}

Many innovations in teaching methods are introduced because of an interest in a particular method or because funds are made available for a particular technology ${ }^{3}$ While the teaching innovations reported in this paper centre on a particular form of small group learning, this is located in the context of a careful redesign of the subject based on an holistic understanding of the various elements that constitute the teaching and learning process in legal education. A substantial body of educational literature ${ }^{4}$ has pointed out that teaching and learning involves an interactive system that can be best described in terms of the relationships between (1) students' background characteristics, (2) the context of learning created by teachers, (3) the approaches to learning adopted by students, and (4) the quality of the resulting learning outcomes. 
Ramsden's statement that "differences in the quality of learning are due to differences in the ways students go about learning; and these differences in turn can be explained in terms of their experience of teaching"5 succinctly encapsulates the essence of these relationships. This system of teaching and learning, is illustrated in Figure 1.

Figure l : A Model for Teaching and Learning Law

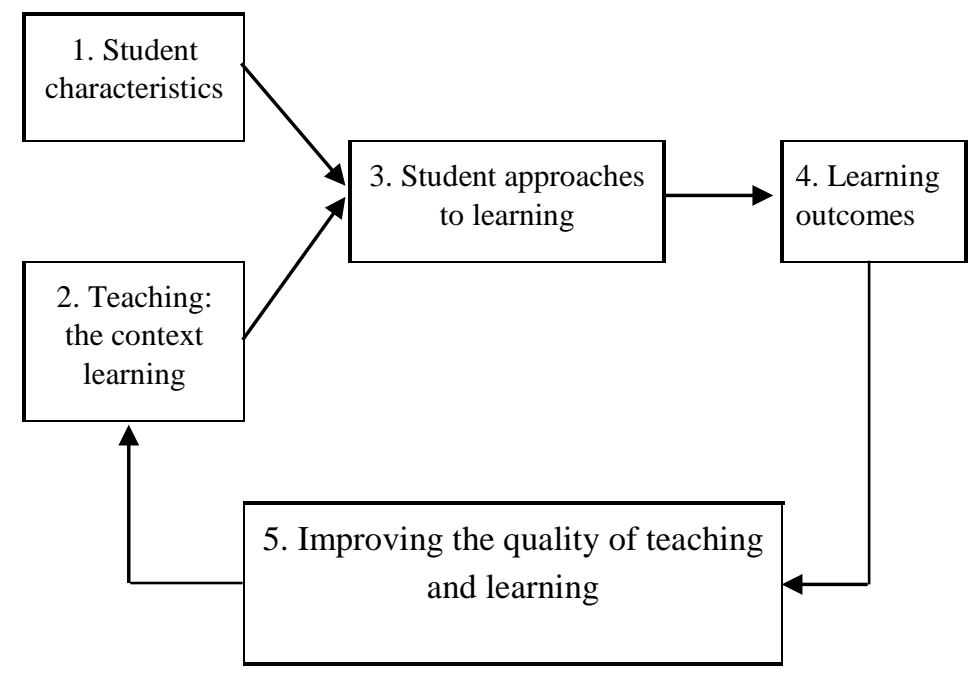

While the above model is essentially descriptive, it can also serve as a guide in planning teaching and learning. We will use the model here as a basis for discussing the key issues considered by the teaching team in the redesign of Contracts.

While the model appears to proceed in a logical, linear fashion, its use in course design is more complex. Thus after noting significant student characteristics (element 1) we will move to element 4, "learning outcomes" as the principal focus of legal education. We then consider the approaches to learning (element 3) that are most likely to lead to these required outcomes and finally, the context of learning (element 2) that will promote such approaches. 


\section{CONTRACTS REDESIGNED}

\section{Student Characteristics (Element 1)}

Students commence the study of law with much in their favour. Owing to the highly competitive nature of entry into law, new law students invariably have a record of considerable achievement in their prior study, having done well at high school and often having successfully completed another degree; they should be capable of succeeding in the study of law. But we also know that the first year law student can experience at least two difficulties. First, irrespective of their prior success in study, they may experience considerable anxiety arising from insecurity in their new situation. They may fear failure, feel alone and isolated and, like students in all disciplines, may experience considerable alienation. ${ }^{6}$ Secondly, few students will have studied law previously — law is different in nature to most high school subjects and most tertiary fields of study, so students usually need to learn how to study law.

Since Contracts is a first-year subject, these abilities and needs must be noted and accommodated by its teaching strategies if students are to succeed.

\section{Intended Learning Outcomes or Aims (Element 4)}

As part of its overall review of the LLB curriculum, the Faculty developed a coherent set of course aims for the LLB. The aims, or intended outcomes, of the Contracts subject took particular cognisance of these general aims, particularly in light of the fact that Contracts constituted one of the students' first experiences of studying law. The intended outcomes of this subject therefore include aims concerned with the generic study of law as well as those associated specifically with the content of Contracts. The revised aims of the Contracts subject are set out in Table 1.

Table l: Intended Learning Outcomes

Contracts seeks to develop in students:

- an understanding of the context of Contract Law;

- a coherent knowledge of the substantive law of contract; 
- the capacity to analyse problems;

- a knowledge of where and how to find the law;

- skills in communication;

- enthusiasm for law as a discipline; and

- an understanding of Contract Law which allows for the integration of new ideas within the students' personal framework.

These aims, or intended learning outcomes, constitute a benchmark against which actual learning outcomes can be measured. It is perhaps important to note that while the aims are all based on a knowledge of the Law of Contract, they require that knowledge to be grounded on personal understanding. The aims seek to bring students into a particular relationship with the law characterised by enthusiasm and personal appropriation.

\section{Student Approaches to Learning (Element 3)}

The relationship between learning outcomes and student approaches to learning is now well established through research in a range of disciplines. ${ }^{7}$ In the case of Contracts, the approach to learning which was considered necessary if the intended outcomes were to be realised is summarised in Table 2 .

Table 2: Required Approach to Learning Contracts

Contracts seeks to encourage students to adopt approaches to learning in which they:

- argue with themselves and others over why the law is as it is

- build up knowledge by consistent and careful reading of cases and materials

- look at relationships between cases

- compare and contrast the development of contract law with other substantive areas of law;

- search for precise definitions of terms.

Readers familiar with the "student approaches to learning" literature will recognise the above approach as essentially a "deep" approach as described by Ramsden, ${ }^{8}$ Biggs, ${ }^{9}$ Marton and Säljö ${ }^{10}$ 
and others and expressed most recently by Entwistle in the Revised Approaches to Studying Inventory ${ }^{11}$ in which deep approaches are characterised by:

- the student's intention to understand;

- an active interest in the subject;

- a constant relation of new ideas to other ideas, underlying principles and personal frameworks;

- and the relation of evidence to conclusions.

The precise nature of deep approaches to learning needs to be established in the context of each specific discipline. ${ }^{12}$ The nature of deep approaches to studying law has not yet been the subject of published empirical research and such research is required before we can confidently describe what constitutes a deep approach to learning law. Though requiring such empirical validation, the required approaches to learning Contracts outlined above from the perspective of a teacher committed to deep as opposed to surface approaches to learning is nevertheless a carefully considered depiction which doubtless reflects the perceptions of many legal academics.

\section{Teaching Strategies: The Context of Learning (Element 2)}

“Teaching” in Contracts is defined as creating a context in which students will adopt the approaches required to achieve the intended learning outcomes. Each part of this context is therefore designed to encourage those approaches and facilitate those outcomes.

Contracts is a year-long subject. It has been divided into eleven modules, each requiring two weeks work. Each module employs four tightly integrated teaching and learning strategies which are outlined in Table 3.

Table 3: Teaching Strategies: The Context of Learning

\begin{tabular}{lllll}
\hline Stage & Method & Time & Aim & Resource \\
\hline 1 & Lecture & 2hrs/ft & $\begin{array}{l}\text { provide conceptual } \\
\text { overview }\end{array}$ & Lecturer
\end{tabular}




$\begin{array}{llll}\text { Individual } & \text { 10hrs/ } & \text { structured learning } & \text { Workbooks } \\ \text { Study } & \mathrm{ft} & \text { through Workbook } & \end{array}$

$\begin{array}{llll}\text { Student } & \text { 2hrs/ft } & \text { co-operative } & \text { Student } \\ \text { Peer } & & \begin{array}{l}\text { learning and the } \\ \text { articulation of ideas }\end{array} & \text { Mentors } \\ \text { Mentor } & & & \\ \text { Group } & & \end{array}$

4

$\begin{array}{lll}\text { Staff led } & 2 \mathrm{hrs} / \mathrm{ft} & \text { testing, clarifying } \\ \text { Seminar } & & \text { and challenging }\end{array}$

Stage 1, the lecture. The lecture provides an overview of the subject matter for each module. Students are given a conceptual framework within which to consider the principles of law they will be studying for that module, as well as an indication of the relative importance of these principles and finally, guidelines for their independent study. The lecture is also an opportunity for the lecturer to convey his or her own enthusiasm for the law in general and for the specific topic under consideration. In terms of the subject's intended outcomes, the lecture is explicitly designed to promote a coherent understanding of the law. In terms of the required approaches to learning, the overview lecture models and emphasises each aspect of the approach to learning that students themselves should take in their own study, ie, the lecture encourages students to raise questions about the nature of Contract Law, emphasises reasoning behind the law and encourages students to relate Contract Law to "real life" as well as to concurrent subjects.

Stage 2, individual study. Within the framework provided by the lecture, students are guided through the required reading of texts and cases by the module workbook (see below). As well as directing their reading, the workbook also requires students to respond to a series of questions and problems. Since their individual responses become the basis of discussion in the student peer mentor groups, individual study commences the process of 
questioning, systematically constructing knowledge, and examining relationships, all of which are essential for successful learning in the subject.

Stage 3, the student peer mentor group. These group meetings provide an environment for students to learn from each other and encourage the development of communication skills and learning how to listen and work with others. In addition the student peer mentor groups provide a network for students to support each other. The groups create an environment for students to argue and test their own understanding of the law, as well as sharing knowledge and resources. This is consistent with the required approaches to learning identified above. In terms of intended outcomes, these groups are powerful vehicles for developing and advancing oral communication skills, enthusiasm for law as a discipline and the capacity of the student to analyse problems. As a unique and pivotal aspect of the subject's teaching strategy, the student peer mentor group is described in some detail below.

Stage 4, the staff-led seminar group. The student composition of the student peer mentor groups and the staff led groups is the same - one week students meet in their peer mentor group, the following week they meet with a staff member. The purpose of the staff led group is to ensure that all students in the group have a basic understanding of the work done to date, to test and assess the knowledge and level of understanding of individuals, to challenge and encourage students and to answer questions on matters of substantive law. This stage in the teaching and learning process seeks to develop in students an understanding of the context of Contract Law and a coherent knowledge base. These desired learning outcomes arise out of the approaches to learning outlined in Table 2.

Stages 1-4: the role of the module workbooks. Printed workbooks are made available to students for each of the eleven modules. The workbooks take students through the module in a structured way. They include the details of prescribed textbook reading, prescribed cases and statutes and refer students to relevant articles. Each workbook moves the student through a series of set exercises from basic questions of definition, to simple applications of the law, to conceptual issues and areas of conflict, to more difficult 
problem questions of the type they might face in an examination. This is followed by an essay question dealing with a complex matter of policy or law reform. ${ }^{13}$ Each workbook concludes with a practical exercise. The workbook is the focus for all four stages of the teaching strategy.

\section{Assessment as Part of the Context of Teaching and Learning}

From the student perspective, assessment "defines the curriculum", indicates to students what is really required in the subject and determines how they will approach learning. Thus Crooks describes assessment as "the hidden curriculum", ${ }^{14}$ while Ramsden cites with approval Rowntree's observation that "if we wish to discover the truth about an educational system, we must look into its assessment procedures". ${ }^{15}$ Tang's detailed study of the influence of varying forms of assessment on student approaches to learning and the quality of learning outcomes provides powerful empirical support for these propositions. ${ }^{16}$ It is clear that any redesign of a subject which fails to take into account the influence of assessment will not succeed in changing students' approaches to learning and consequently will have limited success in achieving its intended outcomes.

The assessment regime for the revised Contracts subject is outlined in Table 4.

Table 4: Assessment

\begin{tabular}{lcl}
\hline Assessment Item & $\begin{array}{c}\text { Weighting } \\
(\%)\end{array}$ & \multicolumn{1}{c}{ Key Purpose } \\
\hline Short research paper & 10 & $\begin{array}{l}\text { enhance research and } \\
\text { written communication } \\
\text { skills }\end{array}$ \\
& 5 & $\begin{array}{l}\text { develop oral skills and } \\
\text { teamwork }\end{array}$ \\
Group mini moot & 25 & $\begin{array}{l}\text { test knowledge of } \\
\text { substantive law }\end{array}$ \\
$\begin{array}{l}\text { First semester } \\
\text { examination }\end{array}$ & &
\end{tabular}


develop research and communication skills by applying them to a complex problem

Second semester

examination

Overall seminar performance
25

test overall knowledge

of the subject and

analytical skills

10

encourage questioning

Item 1: Short research paper. This requires students to submit, early in the semester, a written response to a short problem. There is a defined word limit and a limited amount of time is made available to complete the task. The purpose of the exercise is to develop and test the application of basic written communication skills to a legal problem. In particular students are required to identify one or two issues and write a reasoned legal response.

Item 2: Group mini moot. This involves dividing each of the small groups into teams of three or four. Each team is asked to be prepared to present oral argument either for a plaintiff or a defendant. Any member of the team might be asked to commence or continue with their team's submissions. The mark awarded is a team mark.

Item 3: Semester 1 examination. Examinations in law are important to give professional credibility to the degree. Examinations are also an effective means of testing individual knowledge of substantive law.

Item 4: Assignment, moot or viva. (at the election of the student). ${ }^{17}$ Students may elect to attempt either an assignment, participate as a barrister or solicitor in a formal moot, or take an oral examination. This option recognises that some students are better at demonstrating their understanding by oral argument, others by writing. It also allows for a student to work on their own or as part of a team.

Item 5: Semester 2 examination. This examination seeks to test the 
capacity of the student to give reasoned legal advice from a complex set of facts and issues. As in the first semester examination students are generally required to answer three out of four questions.

Item 6: Seminar performance. The overall contribution made by students in the staff led seminars is assessed — on the quality rather than the quantity of their contributions. Performance is assessed in accordance with the following indicators:

(i) level of attendance at staff led seminars

(ii) participation in class

(iii) preparation for class

(iv) ability to answer questions or clarify vague answers.

While the total context of learning is constituted by each of the teaching and learning strategies and the assessment regime, for us the most interesting aspect of this context is the student peer mentor group, around which many of the elements of the context are centred. Since student peer mentor groups represent a particular form of small group learning, we will first locate these groups in the context of small group learning in general, before examining their more specific features in the subject of Contracts.

\section{SMALL GROUP LEARNING AND THE RATIONALE FOR STUDENT PEER MENTOR GROUPS}

Learning in small groups has a number of widely accepted benefits. Jacques ${ }^{18}$ has summarised these with particular clarity:

Small group discussion provides the opportunity for students not merely to engage in intellectual discourse but also to create a social "family" to which they can belong and become identified with. It also allows students to learn ways of communicating their thoughts, and occasionally feelings, and of gauging their understanding of subject matter firstly by expressing it and secondly by comparing it with the understanding of their peers. Clearly, the atmosphere in the group will determine whether this can be done in an open and co-operative manner as opposed to a closed and competitive one.

In terms of the approaches to learning required in Contracts (Table 3), small groups provide a venue in which, through structured discussion, students can engage in most of the processes associated with the desirable approaches to learning. Equally important for first year students, small groups also have the 
capacity to address many of the psychological and social needs of these students identified in our consideration of student characteristics.

Yet as Jacques also points out, small group teaching often fails to deliver these potential benefits. He notes three problems which can render the small group ineffective as an environment for learning:

- the weight of academic authority and expertise invested in the tutor;

- the inability of tutors (and students) to recognise and try out alternative approaches rather than sticking with a respected tradition;

- a pervading anxiety about assessment with a consequent feeling among students that they should speak only when they have something "safe" to say. ${ }^{19}$

If many of the limitations of small group teaching and learning arise from the perceived authority of the tutor, how can this be overcome? The solution adopted by the Contracts teaching team has been to constitute student peer mentor groups which seek to retain the benefits of small group learning, avoid the potential limitations of the academic-led group, and harness the benefits of another proven form of learner facilitation - the peer mentoring process.

Peer mentoring typically entails using students who have already successfully completed a subject to assist students who are currently studying it. Such students bring a particular expertise to this process since they are able to relate closely to the experience and needs of current students, are familiar with the subject and are also familiar with teachers and their expectations. At the same time, current students are able to relate to their (slightly wiser) peers in an open, friendly and unthreatening way.

The term "peer mentoring" is also used to describe how students engaged in the study of a subject help each other. Such peer support for learning could be described as the "untapped resource" of higher education. Students naturally seek the support of their peers in the extra-curricular activities of their university experience and informally tap the knowledge and understanding of their fellow students in the library, tutorial or laboratory class. The concept of students helping each other to learn and in the process 
consolidating their own learning was proposed by scholars of ancient times, was utilised by Lancaster and Bell in the late 18th century and is again being examined as a viable approach to learning in higher education. ${ }^{20}$

Experience indicates that the constructive use of peer mentoring will promote student autonomy, encourage deep approaches to learning and improve student progression rates and reduce "dropout" rates. ${ }^{21}$ In short peer mentoring contributes to the learning environment in a special way by facilitating some of the learning processes identified in the desired approaches to learning in Table

2. Goldsmith and Goldsmith have summarised the advantages of peer mentoring as fourfold:

- socio-psychological - it offers close personal contact in an otherwise remote environment;

- pedagogical — students are active as learners, teaching enhances learning for the "tutor" and there is increased cooperation, motivation and self-esteem;

- economic — a saving of staff time and energy;

- political — it helps students effectively adjust to the curriculum as a "system". 22

\section{STUDENT PEER MENTOR GROUPS IN CONTRACTS}

\section{The Structure of the Student Peer Mentor Group}

Each group consists of between 12-15 students who meet every second week for a period of two hours. Each meeting generally follows a four-part format:

(i) The group reviews the preceding lecture in order to remind students of the topic's conceptual framework, to identify unclear points and problems arising from the lecture, and to set the scene for the problem solving exercises that follow. This activity supports a coherent frame- work (intended outcome 2) and the systematic building up of this framework (required approach 2).

(ii) The group is encouraged to relate the lecture topic to current events and life experiences; for example the enforceability of an exclusion clause on a parking station ticket or the status of advertisements in newspapers, explicitly encouraging 
component 3 of the required approaches (which looks at relationships between cases, statutes and real life examples in terms of the operation of contractual obligations).

(iii) The group checks for any problems that members may be having - either with the subject specifically or with their study of law in general. This activity is considered particularly important for first-year students new to the study of law.

(iv) The group works systematically through workbook questions they have previously considered in their private study. This aspect requires most components of the required approaches to learning. Problems with questions of law are noted for discussion at the staff led group.

\section{The Role of the Student Peer Mentor}

The student peer mentor is concerned with the process rather than the content of student learning. Their role includes the following:

- acting as a model for successful student behaviours. To assist in this aspect, the peer mentors attend the Contracts lectures and complete the prescribed reading;

- facilitating the small group learning activities, to ensure, for example, that all students participate;

- encouraging a sense of comradeship and mutual support within the group, helping to alleviate any sense of isolation and to promote cooperative learning;

- meeting on a regular basis with academic staff to discuss the progress of the group (but not of individuals).

The role is not one of de facto tutor and peer mentors are not involved at any stage with the assessment of students.

\section{Selection, Training and Remuneration of the Student Peer Mentors}

The student peer mentors were selected from an initial field of 85 applicants. Each was interviewed and selections were made on the basis of the following criteria:

- enthusiasm for the job

- experience with setting up or being part of a study group 
- having received a grade of credit or better in the subject

- understanding of group dynamics

Each student was then required to attend a weekend (residential) training course which focused on the skills of facilitating small group discussion and the role of the student peer mentor.

Peer mentors are paid a base rate for the time they spend attending lectures in the subject and for each of the two hour sessions with their groups. These costs are currently met by means of a Federal Government "Committee for the Advancement of University Teaching” grant. Since an increasing emphasis is being put on the quality of teaching it is hoped that the final evaluation of the scheme will persuade the University to extend the program to an increasing number of subjects. Apart from paying the peer mentors, it is possible to introduce (or continue) the scheme on the basis of the mentors being given academic credit for their participation in terms of an elective. This is consistent with the view that the mentors themselves learn much from their participation. Alternatively, student peer mentors might volunteer their services and energy on the basis that this looks good on their Curriculum Vitae and when given official recognition by the University helps in their employment prospects. ${ }^{23}$

\section{Evaluation of the Student Peer Mentor Program}

The student peer mentor program promises to have a significant impact on a number of aspects of student performance. These include how students adapt to the university environment, how they come to approach the study of law, and the quality of actual learning outcomes. The evaluation of the program is, therefore, a significant undertaking which needs to incorporate a series of related research studies.

In terms of the model for teaching and learning law on which this paper is based, the evaluation of the program centres on questions concerning approaches to learning and learning outcomes.

First then, are students adopting a deep approach to learning? Anecdotal evidence certainly suggests they are. Student peer mentors report that their groups are characterised by students' active engagement in problem solving, seeking connections 
between what they are studying and "real life", arguing about the nature and meaning of the law, and analysing what they are learning in the context of other subjects they are studying. The high level of attendance (consistently over eighty-five per cent) indicates a high level of student engagement. One student's comment that "we learn from each other in a structured setting which is not formal” is a typical sign of student satisfaction. In addition to the above evidence, the students' approaches to learning have been measured at the commencement of the year using the Revised Approaches to Studying Inventory ${ }^{24}$ and will be remeasured at the completion of the subject to test whether the required approaches have in fact been achieved.

The second major concern in evaluating the program is to determine whether the student peer mentoring process has resulted in higher quality learning outcomes. Formal research will involve analysing examination scripts according to accepted methods of measuring the quality of learning ${ }^{25}$ and comparing these scripts with those of the preceding year.

If informal views of students and staff are so far favourable, so too are the perceptions of the student peer mentors. As well as meeting fortnightly with the subject co-ordinator, each has been keeping a weekly diary of their experiences. It is clear that all believe they themselves have benefited greatly from the experience and they are convinced about the benefits which the student peer mentor groups offer to the students. A common comment has been, "Why can't this system be introduced into all of our law subjects?" Extracts from three mentors' diaries are included as an appendix to this paper. These tell the story of the student peer mentor groups in a way we never can.

\section{CONCLUSION}

There is some difficulty in separating the student peer mentor program from the subject as a whole and it is arguable that the positive responses so far reported must be read in the light of the other features of the course structure - including the assessment profile, the workbooks, lecture format and staff led groups.

It is, therefore, important to emphasise that the features outlined in this paper are all integral to the subject as a whole. The student peer mentor program is not an "add on" to help struggling students 
but rather an important component of the subject as a whole. The real test of course is whether students are adopting the desired approaches to learning and achieving the required outcomes. On the evidence to date, we believe that they are and we are confident that the program as it has been designed and implemented can deliver quality learning in this substantive law area.

We are excited by the possibilities provided by this integrated approach, which we believe reflects more closely the wisdom of the early legal educators, that You must "read the law"; You must appropriate it to yourself and make it personal to you. In this way we believe we can lead students to a better understanding of and love for the law.

\section{APPENDIX}

\section{Typical Extracts from the Diary Notes of Three Student Peer Mentors.}

\section{Peer Mentor 1 - (Two Groups)}

I left the sessions on a complete high. I felt the groups were successful in that the group atmosphere was established, the ice broken and the workbooks completed well (not all the questions' parts were done but most of them which was good - in both groups). The groups both enjoyed/appreciated this session and indicated to me that they found the sessions to be very helpful and rewarding. Six individuals separately approached me to thank me for conducting an "excellent” session. This was a very rewarding experience for me even without this expressed gratitude. My second group (which was a very lively one!) was also very satisfied with their progress and understanding of the topics and seem to have bonded extremely well. They have called themselves, "Just the best group there could be". Three members of the group who initially had dissident tendencies were very much decrying this slogan. They thought it was the most worthwhile thing they had done in law school yet. Their initial suggestions or thoughts were that the peer mentor program would be a waste of time, however, they very quickly seemed to experience a complete change of heart.

Some of the people in the second group are crazy cards - 
maybe that is why they enjoyed the group and get so much out of it. The bonding was magnificent. None of them wanted to leave their chairs at the end of the session (I finished both groups a few minutes early because we didn't have a break - they were too excited, or maybe I was - no one mentioned the idea so we kept the ball rolling REALLY FAST). Speaking again of bonding, the group decided at the end of the session that they'd print themselves t-shirts saying "We love contract and we're the best group". Apparently, these people didn't know each other beforehand - at least most of them - except for seeing each other at the previous week's staff-led seminar.

The group's responses to me were excellent. Again the second group had a few rowdy males who tried to endear themselves to me, but that was quickly and effectively played off by me so everything is now very good, ie., we treat each other with mutual respect. The group members seemed to appreciate my function. A couple of times the one above-mentioned girl unashamedly demanded that $I$ tell them the answers, but she soon gave up. I made my role as a facilitator and not a teacher very clear at the start of both sessions. This is what I mean by that girl "testing my limits”. No one else made such demands. I surprised myself how well I handed the situation.

\section{Peer Mentor 2}

For the introductory exercise I paired people with a partner who they didn't know and then had them introduce one another to the group. This worked really well, everyone became really involved in discussion with their partners and I had to cut short the discussions to start on the workbook. There was a fairly comfortable feeling among the group, people had prepared to varying extents and most were prepared to volunteer their knowledge.

There were about three students who were quiet, they didn't ask questions or offer their contribution, I specifically invited them to join in and have their say, I gave one the job of being a scribe. I must continue to actively involve them. Generally, the group had done a lot of work in preparation, they asked some questions which I couldn't answer, I redirected the question until we found someone with a solution to offer, sometimes we had questions which we couldn't resolve and so made a note to refer these questions to a 
tutor. These discussions were very useful as they realised that my role wasn't that of an academic and they also realised how much they had to learn from, as well as to offer one another.

I observed everyone in the group and I think that every single individual gained something from this session. The members of the group showed respect for one another and generally were keen to listen to each other's contributions. I was going to have a break, but new issues kept arising, the group remained interested and the discussions were very productive, so I saw no good point at which to interrupt and we kept going for the full two hours.

Overall, the group mood was comfortable, there was some humour and laughs and there was a great willingness to learn from one another. It was a very positive experience. I must work on encouraging those few quiet people to contribute more.

\section{Peer Mentor 3}

It was not until we began the workbook that the group really started clicking together. Everyone was responding extremely well. The pleasing thing was watching the group learn off each other rather than blatantly directing the question at me and expecting an answer. It seemed to me that they understood the basic concept of the Student Peer Mentoring session, that is, learning from each other. At times, the group did look to me for an answer but this would mainly be on difficult questions of law which no one in the group could answer.

The group was working so well together that I thought that they already knew each other but this wasn't the case. It was amazing how these people were able to interact so well together without even knowing each other. The level of interaction exceeded my expectations indeed. While being serious in discussing the questions at hand, they also were creating a friendly atmosphere in that jokes were told (in relation to the questions) thus there being laughter all round. We were enjoying ourselves at the same time.

At times it felt like I didn't have to do anything, that is, just sit back and steer. There were people volunteering to draw diagrams on the whiteboard without my even asking. They were also keen to read the questions out loud. I was so pleased with their willingness to participate.

On the whole, the group was very active and there was not one 


\section{person who didn't have anything to contribute.}

* Peter MacFarlane is a Senior Lecturer in the Faculty of Law at Queensland University of Technology Brisbane. Gordon Joughin is an Educational Consultant attached to the Faculty of Law. The authors also acknowledge the contribution made by our colleague Frances McGlone to the research, development and implementation of the small group peer mentor learning program.

1 Graham Gibbs, amongst others, has also noted these difficulties. See G Gibbs, Problems and Course Design Strategies (Oxford: The Polytechnics and Colleges Funding Council, 1992).

2 Another first year subject, Torts was also re-designed along similar lines.

3 D Laurillard, Rethinking University Teaching (London: Routledge, 1993, p.181).

4 Particularly well expressed by J Biggs in Teaching for Better Learning (1991) 2 Legal Educ Rev, 138 and From theory to practice: a cognitive systems approach, (1993) 12 Higher Educ Research and Development, 73-85 and summarised in detail in P Ramsden, Learning to Teach in Higher Education (London: Routledge, 1992).

5 Ramsden, supra note 4, at 18.

6 This is supported by a recent study by Lynne Leveson, The First Year Experience: An Experiment in Group Work with University Accounting Students, La Trobe University, Melbourne.

7 Starting with F Marton and R Säljö's seminal paper, On qualitative differences in learning 11 - Outcome as a function of the learner's conception of the task, (1976) 46 British J of Educ Psychology 115-27, and recently summarised in Ramsden supra note 4 at 53-60.

Ramsden supra note 4 at 46.

9 JB Biggs, Student approaches to learning and studying (Melbourne: Australian Council for Educational Research, 1987).

10 F Marton \& R Säljö, On qualitative differences in learning: Outcomes and process, (1976) 46 British J of Educ Psychology 411; Marton and Säljö, supra note 7.

11 N Entwistle, Revised Approaches to Studying Inventory (Edinburgh, 1993).

12 Ramsden notes that "the precise descriptions of surface and deep approaches differ from teacher to teacher, and so from subject area to subject area just as learning outcomes in different subjects obviously vary. But the approaches have enough in common across different tasks to allow us to speak confidently about the universal relevance of the dichotomy they declinate", supra note 4 at 82.

In formulating the levels of questions, regard was had to Bloom's taxonomy as applied to the legal sphere. Refer to N Gronlund, Stating Objectives for Classroom Instruction (New York: Macmillan, 1985), 36-37; DM Tribe \& AJ Tribe; Lawteach: an interactive method for effective large group teaching (1987) 12 Stud in Higher Educ 299 at 302-310.

14 T Crooks Assessing Student Performance (Kensington: Higher Education Research and Development Society of Australasia, 1988) at 6. Ramsden supra 4 at 67.

16 KC Tang, Effects of Different Assessment Procedures on Tertiary Students' Approaches to Studying, unpublished $\mathrm{PhD}$ thesis, University of Hong Kong 1991.

17 For a recent article concerning the operation of viva examinations in this unit see D Butler \& L Wiseman, Viva the Viva: oral examinations in Contract Law (1993) 4 Legal Educ Rev 331.

18 D Jacques, Learning in Groups (London: Kogan Page, 1992) at 70. 
19 Jacques supra note 18, at 90.

20 McRae Peer Tutoring Newsletter May 1983 Vol 4.

21 See for example papers presented at the Peer Tutoring: Learning by Teaching Conference, University of Auckland, New Zealand, 19-21 August 1993.

22 Goldsmith \& Goldsmith cited by D Jaques supra note 18, at 95.

23 We already have anecdotal evidence that some of the peer mentors believe they were given Articles on the basis of their leadership in acting as a peer mentor.

24 Entwistle, supra note 11.

25 Using Biggs' "Structure of observed learning outcomes” typology. See J Biggs \& K Collis, Evaluating the quality of learning: The SOLO taxonomy (New York: Academic Press, 1982). 